\title{
NOVEL APPROACHES FOR THE DETERMINATION OF BIOGENIC AMINES IN FOOD SAMPLES
}

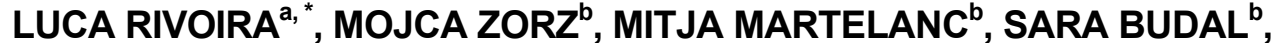 DAVIDE CARENA ${ }^{a, b}$, MLADEN FRANKO $^{b}$, MARIA CONCETTA BRUZZONITI ${ }^{a}$}

\begin{abstract}
Wine is a fermented beverage that could be affected by high concentrations of biogenic amines which alter organoleptic properties.

In this work, new analytical approaches for determination of biogenic amines in wines were developed.

For the first time, we studied the derivatization of BAs in wines with naphthalene2,3-dicarboxaldehyde (NDA) and with dabsyl chloride (DBS) and analysis of derivatized BAs by HPLC coupled to fluorescence (HPLC-NDA-FL) and thermal lens spectrometry (HPLC-DBS-TLS) detectors. The sensitivity of the two methods (LODs HPLC-NDA-FL in the range $27-73 \mu \mathrm{g} / \mathrm{L}$; LODs HPLC-DBS-TLS in the range 3.4-11 $\mathrm{\mu g} / \mathrm{L}$ ) was higher than that of the official method for biogenic amines in wines, OIV-MA-AS315-18 (60-77 $\mu \mathrm{g} / \mathrm{L})$. For its best performances, the HPLC-DBS-TLS technique was applied to the analysis of putrescine, cadaverine, histamine and tyramine in two white wine samples. Additionally, exploiting the Berthelot reaction, the TLS fast screening of biogenic amines in wines, following the release of ammonia by transglutaminase, was also proposed. This approach allowed us to determine total biogenic amount content in concentrations below $0.1 \mathrm{mg} / \mathrm{L}$, expressed as equivalents of histamine.
\end{abstract}

Keywords: biogenic amines, NDA, liquid chromatography, TLS, fluorescence, wine.

\section{INTRODUCTION}

Biogenic amines (BAs) are low molecular weight compounds which could be frequently found in food and beverage matrices [1-2]. They are

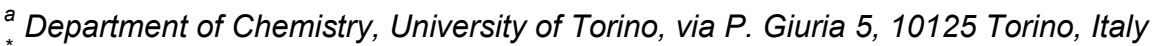

* Corresponding author: luca.rivoira@unito.it

${ }^{b}$ Laboratory for Environmental and Life Sciences, University of Nova Gorica, Vipavska 13, Sl-5000 Nova Gorica, Slovenia
} 
divided in three main classes, aliphatic (e.g. putrescine, cadaverine, spermine, spermidine), aromatic (e.g. tyramine, phenylethylamine) and heterocyclic (e.g. histamine, tryptamine). They mostly derive from four enzymatic reactions of bacteria (decarboxylation, transamination, reductive amination and degradation) performed on precursor amino compounds, such as amino acids.

Highest concentrations of biogenic amines are found in fermented food, where different species of bacteria, in particular lactic acid bacteria (LAB), are responsible for decarboxylase activity, in different degrees depending on the bacteria strain [3]. Lower concentrations are also found in non-fermented foods, as an endogenous origin [4].

Biogenic amines play essential roles in the development, metabolism and physiological functions of humans; however, several studies show that, biogenic amines at concentrations higher than $500 \mathrm{ppm}$ can induce cancerogenic alteration of DNA [5-8]. At lower concentrations, BAs can cause many toxicological effects, such as headache and hypertension besides originating organoleptic alterations of the affected foods. Recently, several European Union Countries have set regulations for limits of histamine (one of the most active amine) in food matrices. As an example, EU Directive 1441/2007 regulates histamine in fish (the mean value must not exceed the value of $100 \mathrm{mg} / \mathrm{kg}$ ) [9]. Local legislation of several countries regulates the concentration of histamine in wines also (i.e. France $8 \mathrm{mg} / \mathrm{L}$, Germany $2 \mathrm{mg} / \mathrm{L}$, Switzerland $10 \mathrm{mg} / \mathrm{L}$ ).

Among the fermented beverages that could be affected by relevant concentrations of BAs, wines are intensively studied matrices. In fact, in these matrices, BAs are produced, along many stages of winemaking and ageing, by $L A B$ bacteria, in concentrations which depend on regional variability, as well as on agricultural and production techniques [10-11]. Histamine, tyramine, putrescine, and cadaverine are among the biogenic amines mainly present in wines [3].

Various analytical methods have been developed for rapid and simultaneous determinations of biological amines in wine, such as liquid chromatography (LC), thin-layer chromatography (TLC) [12], gas chromatography (GC) [13] and capillary electrophoretic methods (CE) [14]. Among these, GC is not so often applied, whereas CE methods are not sensitive to low BA concentrations and have poor reproducibility [15]. Conversely, LC is the most applied technique for the determination of biogenic amines. MS detection is frequently reported, even if its routine application can be limited by the costs and by analyst's expertise required. More frequently, ion [16] and reversed-phase chromatography coupled with UV-Vis and fluorescence (FL) [17] detections are proposed for the analysis 
of BAs. These approaches require a derivatization procedure. Opthalaldehyde (OPA) [18], dansyl-chloride (DNS-Cl) [19], dabsyl-chloride (DBS-Cl)[20] and 6-aminoquinolyl-N-hydroxysuccinimidyl carbamate (AQC) [21] are some of the derivatizing agents used for fluorescence detection. Despite the good sensitivity achieved, the above mentioned derivatizing agents have peculiar disadvantages. More in detail, DNS-Cl is characterized by slow kinetics. OPA can derivatize primary amine groups also at low concentrations (ng/L) but at strictly controlled conditions of $\mathrm{pH}$ [22]. Recently [23], naphthalene-2,3-dicarboxaldehyde (NDA) was used to form derivatives of amines with fluorescent and electroactive properties. If compared with the products formed by derivatization with OPA, the NDA derivatives exhibit improved chemical stability, excitation maxima in the visible region (at 420 and $440 \mathrm{~nm}$ ) and enhanced fluorescence quantum efficiency [24].

These properties, particularly absorption maxima in the visible range, open the possibility of applying novel techniques complementary to $\mathrm{FL}$, such as highly sensitive thermal lens spectrometry (TLS). TLS is however based on radiationless de-excitation processes and is therefore hindered by higher fluorescence quantum yields [25-26]. For nonfluorescing analytes TLS offers detection of absorbances as low as $10^{-7}$, and was shown to actually enable detection at single molecule level when performed in its microscopic configuration (Thermal lens microscopy - TLM) adapted for lab-on-chip detection [27]. Even thought TLS enables sensitive detection also for fluorescing analytes such as cyanobacterial pigments [28], non-fluorescing derivatives such as dabsylated BAs, which have the primary absorbance maximum of BAs shifted into the visible spectral range, appear advantageous over the fluorescing derivatives. Besides an easier matching of absorbance maxima with the available laser emission lines, the longer wavelength further reduces the possibility of interference from other compounds. Due to high sensitivity, fast signal response and capability of probing sub- $\mu \mathrm{L}$ volumes, TLS and TLM have recently found many applications also in vanguard analytical methods for fast screening of environmental and food samples. Such applications include determination of organophosphorous pesticides, microcystin [28], $\mathrm{Cr}(\mathrm{VI})$ [29], and ammonia [30]. As reported, ammonia is also produced from biogenic amines by the action of transglutaminase (TG), which hence can be used for determination of BAs [31].

In this work, for the first time, we compared NDA and dabsyl chloride as derivatizing agents for BAs determination in wines by HPLC coupled to fluorescence (HPLC-FL) and thermal lens spectrometry (HPLCTLS) detectors. Additionally, exploiting the Berthelot reaction, leading to the 
formation of indophenol, we propose for the first time the fast screening of BAs in wines by TLS, following the release of ammonia by TG.

In detail, after a preliminary optimization of chromatographic conditions, the effects of the main derivatization parameters on BA signals were assessed, so optimizing derivatization conditions.

The figures of merit for HPLC-NDA-FL and HPLC-DBS-TLS methods (linearity, limits of detection, limits of quantification) were evaluated and compared. Since the best performances were obtained by the HPLC-DBSTLS method, this method was successfully applied for the determination of putrescine, cadaverine, histamine and tyramine in two white wine samples, comparing results with those obtained by using the official method for BAs determination in wines, which is based on the HPLC-OPA-FL procedure.

\section{RESULTS AND DISCUSSION}

\section{DERIVATIZATION: OPTIMIZATION OF PARAMETERS}

\section{NDA derivatization}

To optimize the derivatization of BAs in wine matrix, the effects of reaction time and initial NDA concentration on the derivatization performance were studied for ethanolamine, chosen as a model compound, in synthetic wine matrix.

\section{Effect of reaction time.}

A solution of $50 \mathrm{mg} / \mathrm{L}$ ethanolamine was derivatized with NDA at six reaction times ranging from 15 to $40 \mathrm{~min}$ and subsequently injected into the HPLC-FL system, measuring the peak area obtained for each trial. As shown in Figure 1, the response increases with reaction time up to $25 \mathrm{~min}$, then reaching a plateau for increased reaction times. In the absence of other literature studies performed on wines, this reaction time was compared with other studies using NDA for BAs derivatization, observing that about $16 \mathrm{~h}$ are required to complete derivatization e.g. in human immunoglobulin samples [17]. This study, tests were performed at reaction times as long as $16 \mathrm{~h}$, highlighted a $30 \%$ decrease of the responses, probably due to degradation of the derivatizing products. Further studies were performed for max. $40 \mathrm{~min}$, choosing $25 \mathrm{~min}$ as optimal reaction time. 


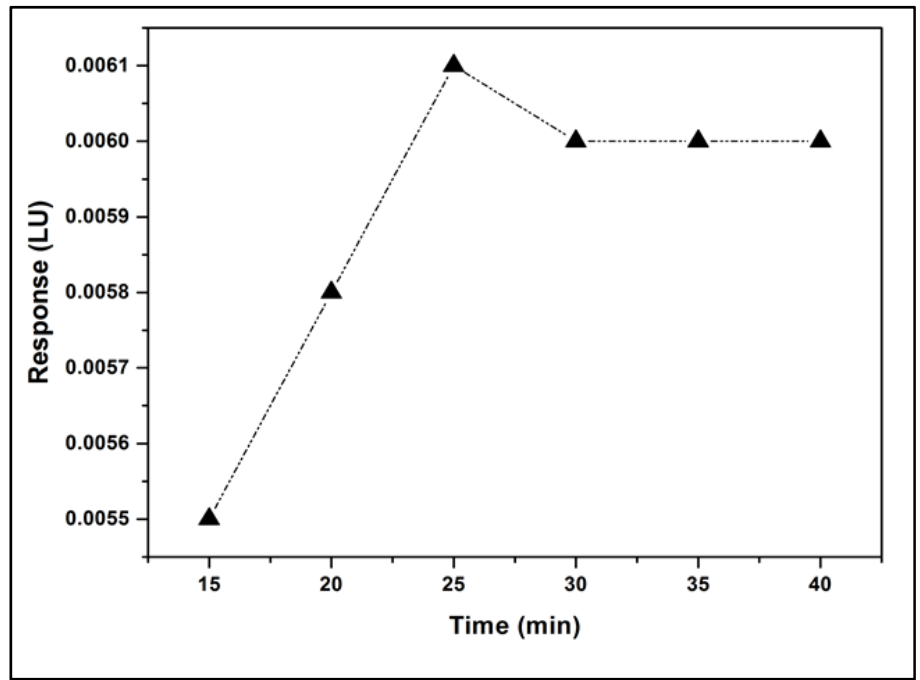

Figure 1. Effect of reaction time in the derivatization of $50 \mathrm{mg} / \mathrm{L}$ ethanolamine in synthetic wine. Response is referred to peak area in HPLC-FL analysis of derivatized amine.

\section{Effect of initial NDA concentration.}

Once identified the optimal reaction time, concentration of NDA necessary to obtain the highest derivatization yields (signal responses) was studied, applying the same detection procedure as detailed before. Studies involving BAs derivatization with NDA in biological human samples point out that concentration of $8 \cdot 10^{-5} \mathrm{M}$ NDA was used to derivatize up to $0.15 \mathrm{mg} / \mathrm{L}$ (corresponding to $8 \cdot 10^{-7} \mathrm{M}$ ) histamine dihydrochloride [17]. Concentration of BAs in wines can achieve tens of $\mathrm{mg} / \mathrm{L}$. Our study was performed under precautionary conditions, considering concentrations of BAs in the range 50-500 $\mathrm{mg} / \mathrm{L}$ in synthetic wine, which cause perceivable alterations of wine such as the reduction in overall wine aroma, observed with the formation of metallic, meaty or putrid aromas in wine. According to the BAs concentration levels studied, the tested NDA concentrations were 1.34 and $13.4 \mathrm{mM}$. Lower NDA concentrations are not advisable, especially for real samples, since derivatization of BAs could not be complete if more than one BA is present (see Figure 2).

Finally, the possibility to increase the derivatization efficiency of biogenic amines was investigated by evaluating the effect of the solvent in which NDA is dissolved. Previous published works reported that NDA could be dissolved both in acetonitrile or methanol, without detailing if a contribution of the solvent in the derivatizing reaction is present $[17,32]$. 
Our study demonstrated that no statistically significant difference is observed when derivatizing with NDA dissolved in methanol or acetonitrile.

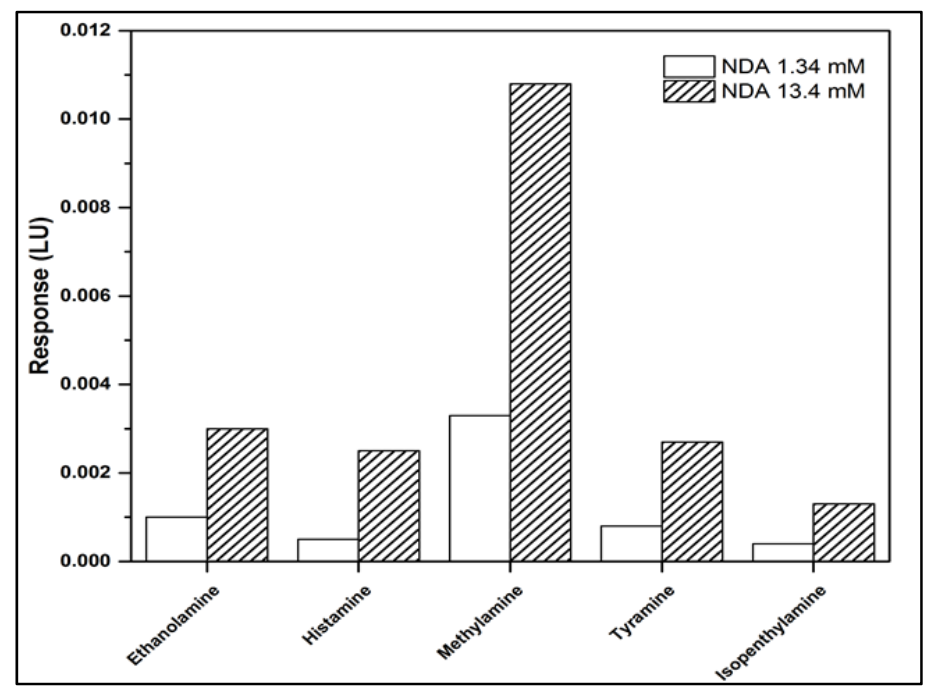

Figure 2. Response area for BAs in synthetic wine derivatized with two different concentration levels of NDA (1.34 and $13.4 \mathrm{mM}$ ). Analysis conditions are detailed in Experimental section.

\section{Dabsyl derivatization}

To optimize the derivatization of BAs, the effects of reaction time, temperature and DBS concentration on the derivatization performance were studied for $5.5 \mathrm{mg} / \mathrm{L}$ putrescine, as a model compound.

\section{Effect of reaction temperature.}

The DBS-putrescine peak area was monitored after heating for 21 min at temperatures ranging from 25 to $70{ }^{\circ} \mathrm{C}$. It must be underlined that, at lower temperatures, dabsyl chloride remains undissolved. The highest reaction efficiency was obtained at $50{ }^{\circ} \mathrm{C}$ as shown in Table 1. Nevertheless, the response obtained at higher temperatures remains within the uncertainty of the experimental error. It should be remarked that at temperature of $50^{\circ} \mathrm{C}$, the efficiency of dabsylation decreases for concentrations of putrescine below $0.5 \mathrm{mg} / \mathrm{L}$. For this reason, derivatization at $70{ }^{\circ} \mathrm{C}$ was chosen for further optimization steps. 
Table 1. Effect of temperature on derivatization of putrescine with DBS.

\begin{tabular}{|c|c|}
\hline$T\left[^{\circ} \mathrm{C}\right]$ & Response [peak area] \\
\hline 25 & $290 \pm 20$ \\
40 & $715 \pm 50$ \\
50 & $830 \pm 50$ \\
60 & $720 \pm 50$ \\
70 & $760 \pm 50$ \\
\hline
\end{tabular}

Effect of reaction time.

As shown in Table 2, the maximum efficiency for dabsylation reaction was achieved already after five minutes; longer derivatization times led to decreased efficiency (however within the limits of experimental error), which can be associated with degradation of the derivatization product.

Table 2. Effect of reaction time on derivatization of putrescine with DBS.

\begin{tabular}{|c|c|}
\hline time [min] & Response [peak area] \\
\hline 5 & $970 \pm 40$ \\
10 & $960 \pm 40$ \\
21 & $900 \pm 40$ \\
\hline
\end{tabular}

\section{Effect of DBS concentration.}

The effect of dabsyl chloride concentration on putrescine derivative peak area was studied for 400 - and 3300 -fold excess with respect to amine concentration, suggesting that higher excess of the reagent resulted in a 7.1-fold increase in dabsylation efficiency.

\section{INDIRECT DETERMINATION OF BAS THROUGH ENZYMATIC RELEASE OF AMMONIA AND INDOPHENOL BLUE REACTION}

During the TG enzymatic reaction with substrate $\mathrm{N}$-carbobenzoxy-Lglutaminylglycine (CBZ-Gln-Gly) and biogenic amines, ammonia is released and detected by exploiting indophenol blue formation in the Berthelot reaction. Detection of structurally different biogenic amines (putrescine, cadaverine, histamine and tyramine) was investigated. Previously optimized Berthelot reaction [30] was used as colorimetric method for detection of biogenic amines based on indophenol blue formation. 


\section{Effect of buffers on TG reaction.}

Optimum $\mathrm{pH}$ for TG is between 6 and 7 , as specified by the producer. On the other side, recommended $\mathrm{pH}$ for indophenol formation is between 8-11.5 [33]. For this reason, a study on buffer influence on indophenol blue reaction in $\mathrm{pH}$ range 6-7 was necessary. Experiments were monitored at $650 \mathrm{~nm}$ by spetroctrophotometry, with phosphate- $(\mathrm{pH}$ $7)$, acetate- $(\mathrm{pH} 6)$ and Tris- $(\mathrm{pH} 7)$ buffers; results have shown that highest sensitivity of biogenic amine determination by TG and indophenol reaction is obtained in phosphate buffer at $\mathrm{pH} 7$ (Figure 3). It should be remarked that TRIS buffer, usually suggested for TG enzymatic activity test protocols, was revealed incompatible with indophenol reaction.

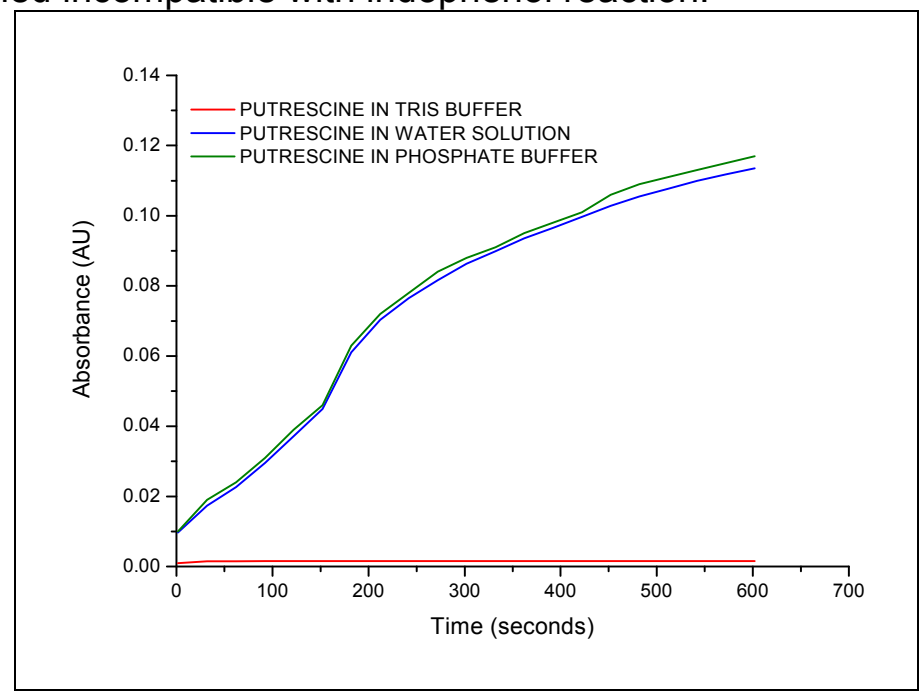

Figure 3. Effect of buffers on kinetics of indophenol formation using $2 \mathrm{mM}$ putrescine as representative biogenic amine. Spectrophotometric detection was performed at $650 \mathrm{~nm}$.

\section{VALIDATION OF HPLC-NDA-FL AND HPLC-DBS-TLS METHODS AND COMPARISON WITH HPLC-NDA-FL AND HPLC-DBS-DAD}

Validation of the novel methods was performed as suggested by European Union (EUR-FA Guide, Annex I) and IUPAC guidelines [34], evaluating the following performance parameters: linearity, limits of detection (LODs) and limits of quantification (LOQs) by analysing standard solutions of putrescine, cadaverine, histamine and tyramine in synthetic wine matrix. LODs and LOQs (see Table 3) were evaluated as $L O D=3 \times S_{x y} / b$ and $L O Q=10 \times$ $\mathrm{SD}_{\mathrm{xy}} / \mathrm{b}$ (where $\mathrm{SD}_{\mathrm{xy}}$ is the standard deviation of the response and $\mathrm{b}$ is the slope of the calibration curve) [35]. 
Table 3. Limits of Detections (LODs) and Limits of Quantitation (LOQs) for BAs obtained by HPLC-NDA-FL, HPLC-DBS-TLS and HPLC-DBS-DAD.

\begin{tabular}{|c|c|c|c|c|c|c|}
\hline \multirow[t]{2}{*}{ BAs } & \multicolumn{3}{|c|}{ LOD $(\mu \mathrm{g} / \mathrm{L})$} & \multicolumn{3}{|c|}{ LOQ ( $\mu \mathrm{g} / \mathrm{L})$} \\
\hline & NDA-FL & DBS-TLS & DBS-DAD & NDA-FL & DBS-TLS & DBS-DAD \\
\hline PUT & 73 & 3 & 15 & 219 & 11 & 50 \\
\hline CAD & 55 & 4 & 23 & 165 & 14 & 77 \\
\hline HIS & 27 & 11 & 85 & 81 & 40 & 282 \\
\hline TYR & 66 & 10 & 86 & 198 & 34 & 288 \\
\hline
\end{tabular}

The linearity of the methods was verified from LOQs to $1.2 \mathrm{mg} / \mathrm{L}$, providing $\mathrm{R}^{2}$ ranging from 0.985 to 0.997 .

It is interesting to note that the detection limits obtained by the newly developed methods are about 10-fold (HPLC-NDA-FL) and 50-fold (HPLC-DBS-TLS) lower if compared with those obtained by CE with indirect UV detection [36] and almost equal (HPLC-NDA-FL) or lower (HPLC-DBS-TLS) to those obtained using direct analysis by CE coupled with mass spectrometric detection [37]. The LODs of the newly proposed methods were lower than those obtained by the official OIV method [38] based on OPA derivatization (i.e. LOD OPA $_{\text {histamine }}=60 \mu \mathrm{g} / \mathrm{L}$; LOD OPA $_{\text {APA }}$ tyramine $=77 \mu \mathrm{g} / \mathrm{L}$ ).

\section{VALIDATION OF ENZYMATIC METHOD}

The performance of the enzymatic method coupled with TLS detection was initially verified by analyzing aqueous solutions with different concentrations levels of single biogenic amines. Results demonstrate acceptable recoveries (118-100\% for putrescine, $70-133 \%$ for cadaverine, $93-112 \%$ for histamine, and $88-108 \%$ for tyramine) and very low limits of detection. The linearity range is rather narrow (from LOQs to $2 \cdot 5 \cdot 10^{-7} \mathrm{M}$ ) due to a TLS signal saturation effect observed for investigated solutions.

When compared to a previously reported method for BA determination by using TG [31], the LODs achieved in this work for standard solutions represent over 450 -fold improvement. In addition to the TLS enhancement of sensitivity by 30 times for the $200 \mathrm{~mW}$ excitation power, such improvement in LOD is attributed also to 13.5-times higher extinction coefficient of indophenol at $650 \mathrm{~nm}$ compared to the extinction coefficient of $\mathrm{NADH}$ absorption maximum at $340 \mathrm{~nm}$, which was related to concentration of BA in the method developed by Punakivi et al. [31]. However, matrix effects hinder the LODs in real samples, which were therefore found up to 3 times higher in the analyzed wines, as reported below (Table 4). Besides the significant improvement of the LODs, it should 
be pointed out that for the previously reported TG method, two hours (reaction time) are required to achieve the indicated LODs, while the newly developed method here described requires just $10 \mathrm{~min}$ of reaction time, thus reducing the total time of analysis by 12 times.

Table 4. LODs and LOQs for batch mode determination of BAs in wine with TG and indophenol reaction on TLS detection unit.

\begin{tabular}{|c|c|c|}
\hline BAs & LOD $[\boldsymbol{\mu g} / \mathbf{L}]$ & $\mathbf{L O Q}[\boldsymbol{\mu g} / \mathbf{L}]$ \\
\hline PUT & 8 & 24 \\
\hline CAD & 10 & 29 \\
\hline HIS & 23 & 68 \\
\hline TYR & 15 & 44 \\
\hline
\end{tabular}

\section{REAL SAMPLE ANALYSIS}

Real samples (Slovenian white wines of Rebula variety) were analyzed to ascertain the presence of biogenic amines using HPLC-DBSTLS since it resulted the best performing method developed according to what previously discussed. Samples were analyzed by applying the standard addition calibration, comparing the obtained concentrations with those obtained by the International method for analysis of biogenic amines in wine [29], i.e. OIV-MA-AS315-18, performed in our laboratory (Table 5). Typical chromatograms obtained for analysis of wine samples by HPLCDBS-TLS are shown in Figure 4.

Table 5. Concentrations ( $\mathrm{mg} / \mathrm{L}$ ) of BAs in wines determined by HPLC-DBS-TLS and HPLC-OPA-FL (official OIV method).

\begin{tabular}{|l|c|c|c|c|c|}
\hline & & PUT & CAD & HIS & TYR \\
\hline \multirow{3}{*}{ Wine A } & DBS-TLS & $0.64 \pm 0.02$ & $0.20 \pm 0.03$ & $0.08 \pm 0.01$ & $<$ LOD \\
\cline { 2 - 6 } & OPA-FL & $0.59 \pm 0.13$ & $0.20 \pm 0.11$ & $<$ LOD & $<$ LOD \\
\hline \multirow{2}{*}{ Wine B } & DBS-TLS & $1.14 \pm 0.03$ & $0.25 \pm 0.03$ & $0.09 \pm 0.01$ & $<$ LOD \\
\cline { 2 - 6 } & OPA-FL & $1.10 \pm 0.23$ & $0.15 \pm 0.08$ & $<$ LOD & $<$ LOD \\
\hline
\end{tabular}

For putrescine and cadaverine, the results obtained by the two HPLC approaches were in good accordance for both wine samples. Due to its higher sensitivity, the HPLC-DBS-TLS method enabled the determination of histamine as well, which could not be determined by the OIV method due to inadequate LODs. 
NOVEL APPROACHES FOR THE DETERMINATION OF BIOGENIC AMINES IN FOOD SAMPLES

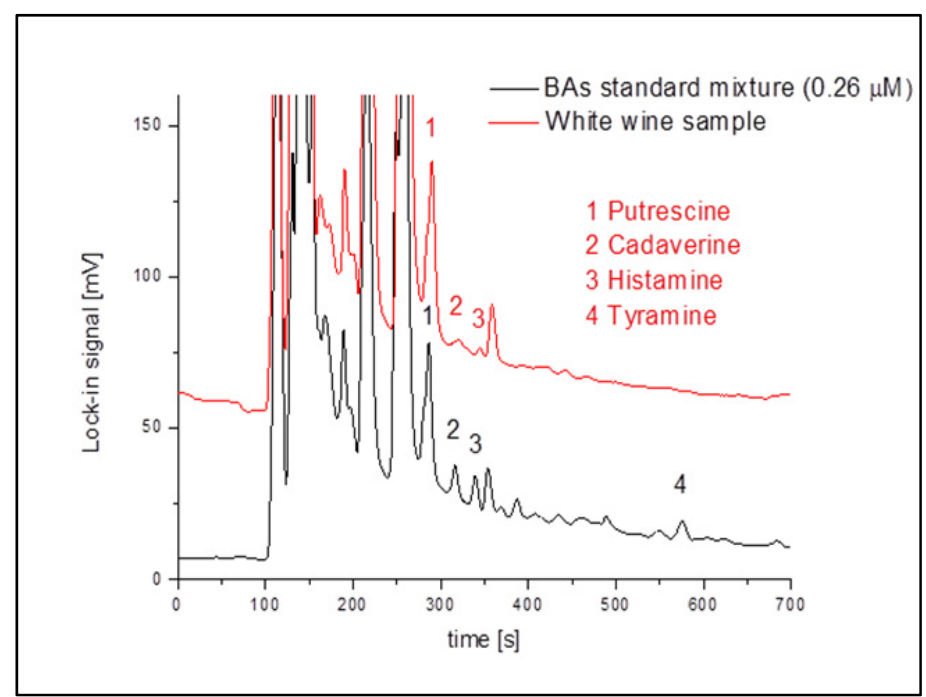

Figure 4. Typical chromatogram obtained for analysis of wine sample by HPLCDBS-TLS

Rebula wines (one home made and one commercial) were additionally analyzed by the newly developed method based on indophenol reaction, through the standard addition procedure to confirm the applicability of the method. Synthetic wine was used as blank.

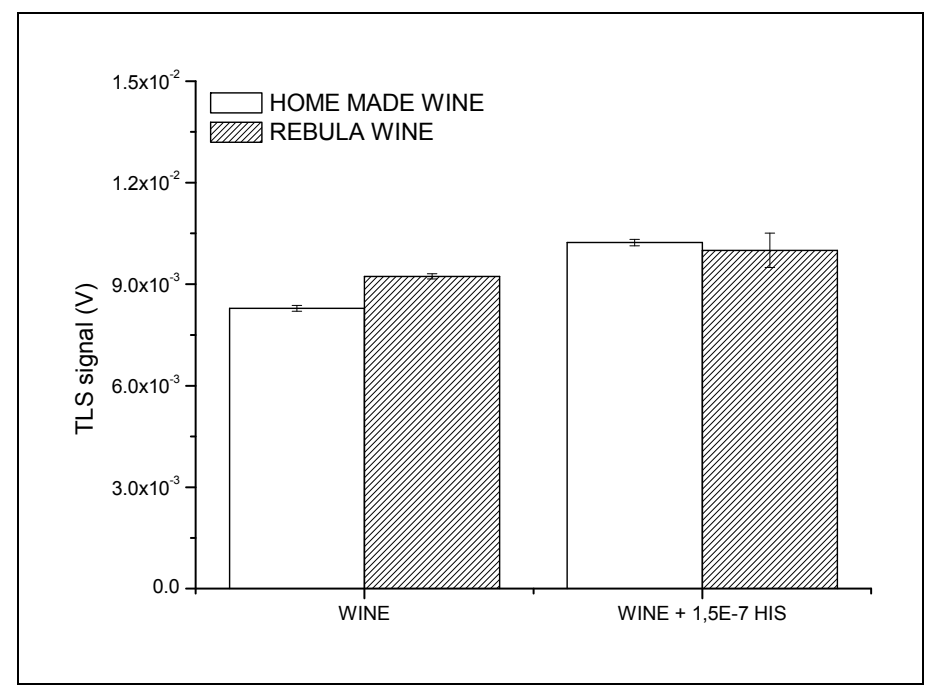

Figure 5. Signals of home made wine and Rebula wine witk TLS detection unit. 
Since the assay is not specific for identification of single biogenic amines, it allows the determination of the total biogenic amines present. As shown in Figure 5, the presence of BAs in samples can be confirmed. Higher signal in case of Rebula wine (commercial), is due to higher concentration of biogenic amines.

The quantity of biogenic amines present in wines was expressed as equivalents of histamine, the only BA for which the maximum contamination level in wine is regulated.

Based on the standard addition of histamine $\left(1.5 \cdot 10^{-7} \mathrm{M}\right)$ and on the difference of TLS signals from spiked and original wine samples, a concentration of BAs corresponding to $(6.4 \pm 0.3) \cdot 10^{-7} \mathrm{M}$ which corresponds to $0.069 \pm 0.003 \mathrm{mg} / \mathrm{L}$ equivalents of histamine were estimated for homemade wine, and $(1.8 \pm 0.9) \cdot 10^{-6} \mathrm{M}$ concentration which corresponds to $0.2 \pm 0.1 \mathrm{mg} / \mathrm{L}$ equivalents of histamine for commercial Rebula wine. These results indicate that the concentrations of $\mathrm{BAs}$ are in good agreement with values found by HPLC-OPA-FL, and also comparable (on the lower range) to the previously reported values (recalculated as histamine equivalents) in Greek wines [33]. Due to the high sensitivity of TLS method, even concentrations below $0.1 \mathrm{mg} / \mathrm{L}$ can still be reliably detected.

\section{CONCLUSIONS}

In this work, naphthalene-2,3-dicarboxaldehyde (NDA) was tested for the first time for the analysis of BAs in wine samples by HPLC with fluorimetric detection. Optimal derivatizing and chromatographic conditions were successfully derived.

The method was validated in terms of linearity, limits of detection and quantification in a synthetic wine matrix. If compared to HPLC-OPA-FL method, the results showed that, despite slightly longer derivatization time (reaction time $25 \mathrm{~min}$ ), the sensitivity of the NDA-FL method is greatly enhanced. It is worth to mention that the analysis time using NDA is about one fourth of the time needed with OPA.

The LODs were importantly decreased by HPLC-TLS using dabsyl chloride (DBS) as derivatizing non-fluorescing agent which provides up to 8.4-fold improvement compared to the HPLC-DAD applying the same chromatographic conditions. The newly developed method was tested on the analysis of BAs in white wine samples, finding good accordance with the results obtained by the standard OIV method for determination of BAs in wines. The newly developed HPLC-TLS method is therefore appropriate for determination of BAs in wine samples. 
High sensitivity of TLS also enables fast detection of BAs by a novel vanguard screening method developed in this work, which is based on enzymatic transformation of BAs into ammonia and further to indophenol which can be sensitively detected by TLS. In real wine samples, BAs can be detected at concentration levels of $10^{-7} \mathrm{M}$ with over 10 times improved sample throughput compared to previously reported enzymatic methods.

\section{EXPERIMENTAL SECTION}

Chemicals

Biogenic amine standards studied were: putrescine-2 $\mathrm{HCl}$ (PUT), cadaverine (CAD), bought from Sigma Aldrich (Seelze, Germany), histamine (HIS), from Panreac Applichem (Darmstadt, Germany), and tyramine (TYR), from Alfa Aesar (Karlsruhe, Germany). Dabsyl-chloride was from Alfa Aesar. All other standards and reagents were bought from Sigma Aldrich and were of analytical grade.

High-purity water $\left(18.2 \mathrm{M} \Omega \cdot \mathrm{cm}\right.$ resistivity at $\left.25^{\circ} \mathrm{C}\right)$, produced by a Thermo Scientific Barnstead NANOpure Water Purification Systems (Barnstead, Germany) was used for standard solution and eluent preparation.

Microbial transglutaminase (TG) (E.C. 2.3.2.13, $1670 \mathrm{nkat} / \mathrm{g}$ ) was purchased from Ajinomoto Co. INC., Japan (Europe Sales GMBH, Hamburg, Germany) and N-carbobenzoxy-L-glutaminylglycine (CBZ-GlnGly) was purchased from Sigma-Aldrich.

For the Berthelot reaction, sodium salicylate $(99.5 \%)$ purchased from Sigma-Aldrich, sodium hydroxide from Riedel-de-Haën (Seelze, Germany), solution of sodium hypochlorite (Pejo, Slovenia), potassium sodium tartrate tetrahydrate $(99 \%)$ and manganese sulfate monohydrate (98\%) from Fluka (Seelze, Germany) were used.

\section{Preparation of solutions}

\section{Derivatizing solutions}

$3 \mathrm{mM}$ o-pthalaldehyde (OPA) solution was prepared by dissolving $20 \mathrm{mg}$ OPA in $50 \mathrm{~mL}$ methanol (the solution must be stored in dark conditions and should be prepared daily). $13.4 \mathrm{mM}$ naphthalene-2,3dicarboxaldehyde (NDA) solution was prepared by dissolving $12.3 \mathrm{~g} \mathrm{NDA}$ in $5 \mathrm{~mL}$ acetonitrile. Both derivatization reactions should occur at controlled basic $\mathrm{pH}$, therefore a $0.1 \mathrm{M}$ borate buffer $(\mathrm{pH} 10.5)$ was used. In case of NDA, borate buffer contains $0.09 \mathrm{M} \mathrm{KCN}$. $1.3 \mathrm{mM}$ NDA was prepared by $10-$ fold dilution of $13.4 \mathrm{mM}$ solution in $0.1 \mathrm{M}$ borate buffer. 
The dabsyl chloride (DBS) solution was prepared by diluting $40 \mathrm{mg}$ of dabsyl chloride in $10 \mathrm{~mL}$ of acetone, followed by 15 min ultrasonic treatment (Iskra PIO, Sonis GT, Slovenia), to obtain the final $12.4 \mathrm{mM}$ concentration.

\section{Solutions for enzymatic reaction}

Standard solutions of BAs were prepared in water and stored in glass vials at $4^{\circ} \mathrm{C}$. Donor substrate $(2 \mathrm{mM}) \mathrm{N}$-carbobenzoxy-Lglutaminylglycine (CBZ-GIn-Gly) was prepared in water. The TG enzyme was dissolved in cold water to obtain enzyme activity $16.7 \mathrm{nkat} / \mathrm{mL}$ (1 $\mathrm{U} / \mathrm{mL}$ ). Solutions for indophenol reaction. Two mixtures of reagents were used for indophenol blue reaction [39]. Mixture A: $10 \mathrm{~mL}$ of sodium salicylate $(1.5 \mathrm{M}), 10 \mathrm{~mL}$ of sodium potassium tartrate tetrahydrate $(30 \mathrm{~g} / \mathrm{L})$ and $2 \mathrm{~mL}$ of manganese sulphate monohydrate $\left(2.5 \times 10^{-3} \mathrm{M}\right)$. Mixture $\mathrm{B}: 10$ $\mathrm{mL}$ of sodium hydroxide $(0.5 \mathrm{M})$ and $10 \mathrm{~mL}$ of commercial bleach (source of hypochlorite). Each mixture was freshly prepared daily.

\section{Synthetic wine (HPLC-NDA-FL)}

This sample $(1 \mathrm{~L})$ was prepared by dissolving $3.5 \mathrm{~g}$ tartaric acid in $120 \mathrm{~mL}$ ethanol and acidifying with $\mathrm{HCl}$ to $\mathrm{pH} 3.5$. Stock solutions of biogenic amines were prepared in synthetic wine for NDA derivatization; their concentrations were $50.6 \mathrm{mg} / \mathrm{L}(0.83 \mathrm{mM})$ ethanolamine, $487 \mathrm{mg} / \mathrm{L}$ $(2.64 \mathrm{mM})$ histamine $\cdot 2 \mathrm{HCl}, 114 \mathrm{mg} / \mathrm{L}(1.70 \mathrm{mM})$ methylamine $\cdot \mathrm{HCl}, 158$ $\mathrm{mg} / \mathrm{L}(0.90 \mathrm{mM})$ tyramine $\cdot \mathrm{HCl}, 150 \mathrm{mg} / \mathrm{L}(1.70 \mathrm{mM})$ isopenthylamine, 118 $\mathrm{mg} / \mathrm{L}(1.62 \mathrm{mM})$ butylamine.

\section{BAs standards (HPLC-DBS-TLS}

Standards were prepared as $2.5 \mathrm{mM}$ solutions by diluting the hydrochloride salts in $0.1 \mathrm{M} \mathrm{HCl}$, containing $0.2 \%$ (w/v) 3,3'-thiodipropionic acid (TDPA, Merck, Germany). An appropriate volume of the stock solution (or $1 \mathrm{~mL}$ of white wine) was afterwards transferred in a $10 \mathrm{~mL}$-beaker and the $\mathrm{pH}$ was adjusted to 8.2 with $\mathrm{Na}_{2} \mathrm{CO}_{3}$ buffer.

\section{Derivatizing reactions}

OPA: the reaction was performed according to the indications reported within the Compendium of International Methods of Analysis [38]. Derivatization of BAs is performed according to a two-steps reaction. In detail, in a flask, $500 \mu \mathrm{L}$ of OPA solution are mixed with $500 \mu \mathrm{L}$ of borate 
buffer and $150 \mu \mathrm{L}$ of 2-mercaptoethanol. In another vial, $500 \mu \mathrm{L}$ of the sample or synthetic wine solution containing biogenic amines at proper concentration are mixed with $500 \mu \mathrm{L}$ of methanol; then $150 \mu \mathrm{L}$ of this latter solution are spiked into solution in the first flask and, after a reaction time of $1 \mathrm{~min}$, the solution is injected in the HPLC system.

NDA: $500 \mu \mathrm{L}$ of the sample or synthetic wine solution containing biogenic amines are mixed with $200 \mu \mathrm{L}$ of methanol, $50 \mu \mathrm{L}$ of borate buffer containing potassium cyanide and $200 \mu \mathrm{L}$ of NDA solution. The optimized reaction time was 20 min (see Results and Discussion section).

DBS-Cl: $500 \mu \mathrm{L}$ of the BA (wine) buffer was transferred into an amber glass vial and $220 \mu \mathrm{L}$ of the dabsyl chloride was added. The reaction mixture was heated in water bath at $70{ }^{\circ} \mathrm{C}$ for $5 \mathrm{~min}$. Afterwards, $610 \mu \mathrm{L}$ of the dilution solution, containing acetonitrile, eluent $A$ and ethanol in the ratio $2: 1: 1(\mathrm{v} / \mathrm{v} / \mathrm{v})$, was added to dissolve the remaining dabsyl chloride in the vial and heated at $70{ }^{\circ} \mathrm{C}$ for further $\approx 5 \mathrm{~min}$.

HPLC mobile phases were prepared from the following solutions $A$ : $0.05 \mathrm{M}$ sodium acetate: tetrahydrofuran $(96: 4 \mathrm{v} / \mathrm{v})$ and $\mathrm{B}$ : methanol, by gradient mixing as detailed in Table 6.

Table 6. Gradient conditions used for the separation of biogenic amines derivatized with NDA and OPA

\begin{tabular}{|c|c|c|c|c|c|}
\hline \multicolumn{3}{|c|}{ NDA derivatization } & \multicolumn{3}{c|}{ OPA derivatization } \\
\hline Time $[\mathrm{min}]$ & $\% A$ & $\% B$ & Time $[\mathrm{min}]$ & $\% A$ & $\% B$ \\
\hline 0 & 30 & 70 & 0 & 80 & 20 \\
\hline 11 & 30 & 70 & 15 & 70 & 30 \\
\hline 25 & 25 & 75 & 23 & 60 & 40 \\
\hline 40 & 10 & 90 & 42 & 50 & 50 \\
\hline 50 & 10 & 90 & 55 & 35 & 65 \\
\hline 60 & 30 & 70 & 60 & 35 & 65 \\
\hline & & & 70 & 80 & 20 \\
\hline & & & 95 & 80 & 20 \\
\hline
\end{tabular}

Experiments indicated that the presence of thetrahydrofuran (THF) in the mobile phase has two effects on the elution of BAs derivatized with NDA: it decreases the total time of the analysis and it increases the peak response (from 13 to $25 \%$ depending on BAs). The optimized total time of the elution for HPLC-NDA-FL is $25 \mathrm{~min}$, about one fourth of the time needed to analyse BAs with OPA derivatization. 
For dabsylation: The eluent was prepared as solvent $A$ - solvent $B$ composition of $35: 65 \% \mathrm{v} / \mathrm{v}$. Solution $\mathrm{A}: 4.0 \cdot 10^{-2} \mathrm{M}$ sodium acetate with $10 \%$ $(\mathrm{v} / \mathrm{v})$ dimethylformamide and $0.23 \%(\mathrm{v} / \mathrm{v})$ triethylamine, adjusted to $\mathrm{pH} 5.0$ with diluted acetic acid); solution B: acetonitrile, $t$-butylmethyl ether and water (87.5:10:2.5, v/v/v).

\section{Enzymatic and Berthelot reaction}

For determination of BAs, $1 \mathrm{~mL}$ of CBZ-Gln-Gly, $1 \mathrm{~mL}$ of enzyme solution and $1 \mathrm{~mL}$ of $B A$ of interest were introduced into a $10 \mathrm{~mL}$-flask. Afterwards, $1 \mathrm{~mL}$ of each mixture ( $A$ and $B$ ) was added to the enzymatic mixture and diluted with buffer and acetonitrile (total $25 \% \mathrm{v} / \mathrm{v}$ ) to obtain the final volume of $10 \mathrm{~mL}$. After 10 minutes, $2 \mathrm{~mL}$ of the solution was transferred into a quartz cuvette (batch mode measurement) and introduced in a TLS cuvette holder.

White wine samples were tested for the presence of studied BAs, all experiments were done with phosphate-diluted wine samples to reach basic $\mathrm{pH}$.

Instrumentation

HPLC-FL system

An Agilent 1100 chromatograph (Agilent, Santa Clara, CA, USA) equipped with a Kinetex EVO ( $250 \mathrm{~mm} \times 4.6 \mathrm{~mm}$ I.D., $5 \mu \mathrm{m}$ particle size $)$ with a $4 \mathrm{~mm} \times 3 \mathrm{~mm}$ I.D. guard column (Phenomenex), a 10 $\mu \mathrm{L}$-injection loop and a fluorescence detector was used. Eluent flow rate was set at $1.0 \mathrm{~mL} / \mathrm{min}$, while fluorescence detector was set at $356 \mathrm{~nm}$ (absorbance wavelength) and 445 $\mathrm{nm}$ (emission wavelength). Chromatographic data were handled by OriginPro 8.5 software, without any data correction or smoothing.

HPLC-TLS system

The dual-beam thermal lens spectrometer used in this work is schematically presented in Figure 6. It consists of a Kripton laser (Innova $300 \mathrm{C}$, Coherent, USA) operating at $413 \mathrm{~nm}(35 \mathrm{~mW}-150 \mathrm{~mW})$, which provides the pump beam, and a He-Ne probe laser (Model 1103P, Uniphase, USA) of $2 \mathrm{~mW}$ output power $(632.8 \mathrm{~nm})$. The pump beam was modulated with a mechanical chopper (300CD, Scitec Instruments, UK) at $28 \mathrm{~Hz}$ and focused onto the sample cell with a $100 \mathrm{~mm}$ focal length lens (L1). The probe beam was focused using two lenses with focal lengths of $100 \mathrm{~mm}$ (L2) and $60 \mathrm{~mm}$ (L3). To obtain a collinear propagation of pump 
and probe beams, a dichroic mirror ( $T: 633 \mathrm{~nm}, \mathrm{R}: 410 \mathrm{~nm})$ was used. Thermal lens signal was detected using an amplified photodiode detector (Thorlabs, USA) equipped with a $633 \mathrm{~nm}$ interference filter (Melles Griot, USA) and connected to a lock-in amplifier (SR830 DSP, Standford Research, USA, $1 \mathrm{~s}$ time constant), which was further connected to a PC for data treatment and storage. The chromatographic system consisted of a HPLC pump (Smartline pump 1000, Knauer, Germany), a metal free manual injection valve (Knauer, Germany) for liquid chromatography equipped with $10 \mu \mathrm{L}$ injection loop. The column was the same as for HPLCFL system. Detection was performed in an $8 \mu \mathrm{L}$ flow-through cell (Hellma, UK) with $10 \mathrm{~mm}$ optical path length.

\section{TLS detection unit for indophenol blue measurements}

The TLS detection unit was identical to the one described for HPLCTLS system, with the only difference that the Kr-laser was operating at 647 $\mathrm{nm}(200 \mathrm{~mW})$ and the probe beam source was a He-Ne laser operating at $543.5 \mathrm{~nm}$ ( $5 \mathrm{~mW}$, MellesGriot, Carlsbad, California, USA). The dichroic mirror and the interference filter were replaced accordingly to enable transmission at $543.5 \mathrm{~nm}$ and reflection of the pump beam. The flowthrough cell is replaced with a $10 \mathrm{~mm}$ quartz cuvette.

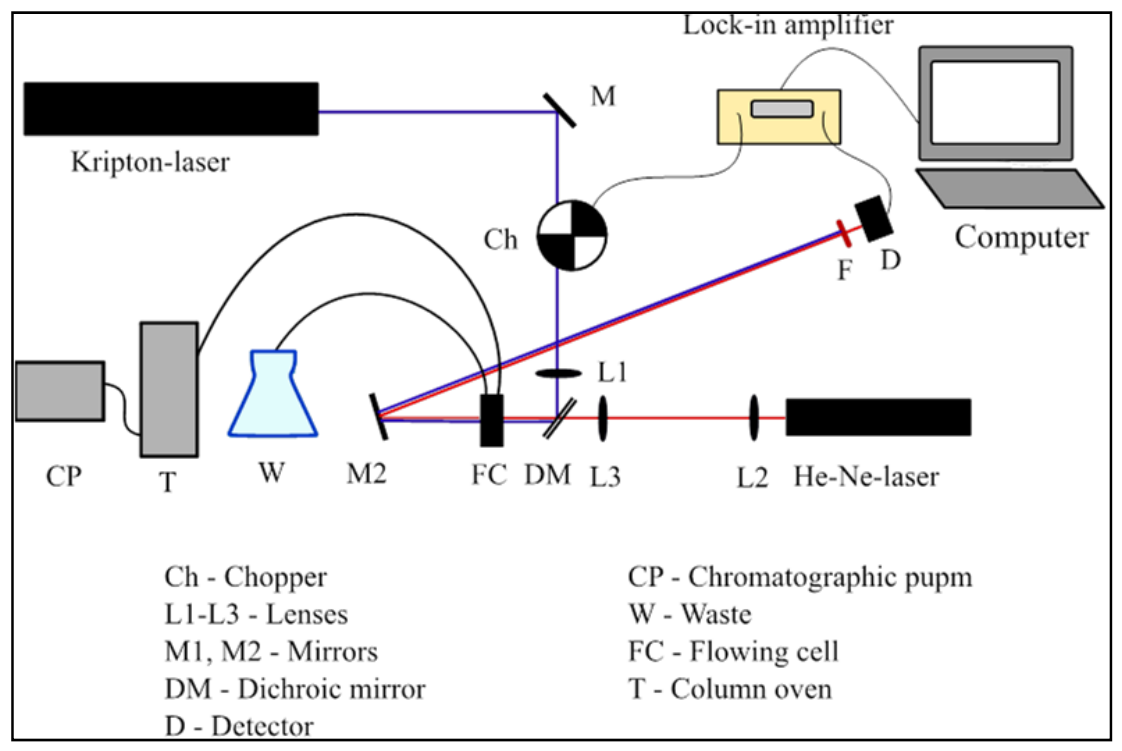

Figure 6. Schematic presentation of a HPLC-TLS system 
Wine samples

Wine samples of Rebula variety were from producers in the ObalnoKraška wine growing region in Slovenia. All wines were produced using the classic procedures of crushing, pressing, fermentation, filtration and bottling.

Samples were stored in 0.75 stoppered dark glass bottles, and kept at 4 deg. $C$ until analysis. For the analysis, $2 \mathrm{~mL}$ of the sample was filtered through a 0.45 nylon syringe filter to remove suspended solids. $500 \mu \mathrm{L}$ aliquot of the filtrate was then derivatized with OPA and DBS as described above, and injected for HPLC analysis.

\section{ACKNOWLEDGEMENTS}

Part of this work was performed under the bilateral scholarship Slovenia-Italy funded by the Centre of the Republic of Slovenia for Mobility and European Educational and Training Programmes (CMEPIUS). Financial support from Ministero dell'Istruzione, Università e Ricerca (MIUR, Italy) is gratefully acknowledged. On Slovenian side, this research was supported by the ARRS research program grant P1-0034 and young researcher grants to M.Ž. and S.B.

\section{REFERENCES}

1. M. H. S. Santos, International Journal of Food Microbiology 1996, 29, 213.

2. J. E. Stratton, R. W. Hutkins, S. L. Taylor, Journal of Food Protection 1991, $54,460$.

3. Y. Y. Guo, Y. P. Yang, Q. Peng, Y. Han, International Journal of Food Science \& Technology 2015, 50, 1523.

4. A. Önal, Food Chemistry 2007, 103, 1475.

5. R. Tofalo, G. Perpetuini, M. Schirone, G. Suzzi, Encyclopedia of Food and Health 2016, 1, 424.

6. V. Ladero, M. Calles-Enríquez, M. Fernández, M. A Alvarez, Current Nutrition \& Food Science 2010, 6, 145.

7. T. Komprda, R. Burdychová, V. Dohnal, O. Cwiková, P. Sládková, H. Dvořáčková, Food Microbiology 2008, 25, 219.

8. A. Naila, S. Flint, G. Fletcher, P. Bremer, G. Meerdink, Journal of Food Science 2010, 75, R139.

9. E. Directive, Official Journal of European Union 2007.

10. M. García-Marino, Á. Trigueros, T. Escribano-Bailón, Journal of Food Composition and Analysis 2010, 23, 455. 
11. O. Martínez-Pinilla, Z. Guadalupe, Z. Hernández, B. Ayestarán, European Food Research and Technology 2013, 237, 887.

12. A. Romano, H. Klebanowski, S. La Guerche, L. Beneduce, G. Spano, M.-L. Murat, P. Lucas, Food Chemistry 2012, 135, 1392.

13. S. Cunha, M. Faria, J. Fernandes, Journal of Agricultural and Food Chemistry 2011, 59, 8742.

14. D. Daniel, V. B. dos Santos, D. T. R. Vidal, C. L. do Lago, Journal of Chromatography A 2015, 1416, 121.

15. P. Ginterová, J. Marák, A. Staňová, V. Maier, J. Ševčík, D. Kaniansky, Journal of Chromatography B 2012, 904, 135.

16. R. Conca, M. C. Bruzzoniti, E. Mentasti, C. Sarzanini, P. Hajos, Analytical Chimica Acta 2001, 439, 107.

17. J.-H. Kim, I. S. Shin, Y. K. Lee, H. J. Oh, S. J. Ban, Osong Public Health and Research Perspectives 2011, 2, 127.

18. N. H. Kim, Y. Park, E. S. Jeong, C.-S. Kim, M. K. Jeoung, K. S. Kim, S.-H. Hong, J.-K. Son, J. T. Hong, I.-y. Park, Archives of Pharmacal Research 2007, 30, 1350.

19. J. Hernández-Borges, G. D’Orazio, Z. Aturki, S. Fanali, Journal of Chromatography A 2007, 1147, 192.

20. A. Bockhardt, I. Krause, H. Klostermeyer, Zeitschrift für Lebensmitteluntersuchung und-Forschung A 1996, 203, 65.

21. P. Hernández-Orte, A. Peña-Gallego, M. J. Ibarz, J. Cacho, V. Ferreira, Journal of Chromatography A 2006, 1129, 160.

22. R. E. Anlı, M. Bayram, Food Reviews International 2008, 25, 86.

23. Q. Weng, W. Jin, Electrophoresis 2001, 22, 2797.

24. P. De Montigny, J. F. Stobaugh, R. S. Givens, R. G. Carlson, K. Srinivasachar, L. A. Sternson, T. Higuchi, Analytical Chemistry 1987, 59, 1096.

25. M. Franko, Applied Spectroscopy Reviews 2008, 43, 358.

26. M. Franko, C. D. Tran, "Thermal Lens Spectroscopy". In Encyclopedia of Analytical Chemistry, John Wiley \& Sons, Ltd: 2010.

27. T. Kitamori, M. Tokeshi, A. Hibara, K. Sato, Analytical Chemistry 2004, 76, 52 A.

28. M. Franko, M. Liu, A. Boškin, A. Delneri, M. A. Proskurnin, Analytical Sciences 2016, 32, 23.

29. M. Liu, S. Malovrh, M. Franko, Analytical Methods 2016, 8, 5053.

30. S. Budal, M. Martelanc, T. Radovanović, M. Franko, International Journal of Environment and Health 2014, 7, 101.

31. K. Punakivi, M. Smolander, M.-L. Niku-Paavola, J. Mattinen, J. Buchert, Talanta 2006, 68, 1040.

32. A. Zotou, M. Notou, Analytical and Bioanalytical Chemistry 2012, 403, 1039.

33. C. Proestos, P. Loukatos, M. Komaitis, Food Chemistry 2008, 106, 1218.

34. G. Simone, P. Robouch, "EURL-FA Guide: Protocol for verification studies of single laboratory/in-house validated methods. Working document v3. 00" European Commission, Directorate-General Joint Research Centre. https:/lec. europa. eu/jrc/sites/default/files/EURLFA-technical\% 20guide\% 20 for $\%$ 20validation\% 20and\% 20verification\% 20v: 2014. 
L. RIVOIRA, M. ZORZ, M. MARTELANC, S. BUDAL, D. CARENA, M. FRANKO, M. C. BRUZZONITI

35. A. Shrivastava, V. B. Gupta, Chronicles of Young Scientists 2011, 2, 21.

36. L. Arce, A. Ríos, M. Valcárcel, Journal of Chromatography A 1998, 803, 249.

37. B. Santos, B. M. Simonet, A. Ríos, M. Valcárcel, Electrophoresis 2004, 25, 3427.

38. OIV, Compendium of International Methods of Wine and Must Analysis, OIV Paris: 2013.

39. T. Tsuboi, Y. Hirano, Y. Shibata, S. Motomizu, Analytical Sciences 2002, 18, 1141. 